\title{
FAMÍLIAS E ESCOLAS: ARRANJOS DIVERSOS
}

\author{
FAMILIES AND SCHOOLS: DIVERSE ARRANGEMENTS \\ FAMILIAS Y ESCUELAS: DIVERSOS ACUERDOS
}

RESUMO: Este artigo discute e analisa os vínculos entre famílias e escolas tendo como núcleo da reflexão a apresentação de diferentes aspectos da instituição doméstica. Para isso, procede a uma discussão acerca do conceito de família a partir da teorização antropológica. Em seguida, apresenta o modo como a família vem sendo objeto de pesquisa em estudos nacionais e os vínculos entre famílias e a instituição escolar com a finalidade de discutir as representações estereotipadas sobre a unidade doméstica, o modo de atuação de seus integrantes, inclusive do pai e dos irmãos sobre o processo de escolarização, e para trazer à baila a importância dos afetos do pai e da mãe nesse processo.

Palavras-chave: Família e Escola. Arranjos Familiares. Afetos Parentais. Processo de Escolarização. Famílias de Camadas Populares.

ABSTRACT: This article discusses and analyses relationships between families and schools, focusing mostly on different aspects of the household as an institution. For that, we develop a discussion about the concept of family based on anthropological theorization. It follows to present the way the family has been studied in Brazil, the relationships among families and the school as an institution. Our objective is to discuss stereotypical representations of the household unity, its members' act and behavior, as well as the father and siblings in the schooling process, in order to bring up the importance of mother and father's affectivity in this process.

Keywords: Family and School. Family Arrangements. Parental Affection. Schooling Process;. Low Income Families.

RESUMEN: Este artículo discute y analiza los vínculos entre familias y escuelas teniendo como núcleo de reflexión la presentación de diferentes aspectos de la institución doméstica. Para ello, procede a una discusión acerca del concepto de familia a partir de la teorización antropológica. A continuación presenta el modo como la familia viene siendo objeto de investigación en estudios nacionales, los vínculos entre familias y la institución escolar; con la finalidad de discutir las representaciones estereotipadas sobre la unidad doméstica, y el modo en que la actuación de sus integrantes, incluyendo al padre y a los hermanos, influye sobre el proceso de escolarización, para de esta manera suscitar el tema de la importancia de los afectos del padre y de la madre en dicho proceso.

Palabras clave: Familia y Escuela. Acuerdos Familiares. Afectos Parentales. Proceso de Escolarización. Familias de Clases Trabajadoras. 


\footnotetext{
* Este artigo é uma versão abreviada de palestra proferida a convite da Profa. Dra. Nadir Zago no Programa de Pós-Graduação em Educação da Universidade Comunitária da Região de Chapecó (UNOCHAPECÓ) em 17 de agosto de 2015.

*** Professor aposentado e professor sênior da Faculdade de Filosofia, Ciências e Letras de Ribeirão Preto -Universidade de São Paulo (USP). Doutor em Ciências Humanas, na área de Antropologia, da Faculdade de Filosofia, Letras e Ciências Humanas da USP.
}

\section{APRESENTAÇÃo}

Este artigo discute e analisa alguns vínculos entre famílias e escolas, tomando como ponto central a instituição doméstica. Para apresentar essa temática, situam-se inicialmente alguns estudos sobre famílias a partir da perspectiva da Antropologia cujos fundamentos metodológicos e teóricos orientam a análise. Na sequência, discutem-se modos da organização doméstica e estabelecem-se algumas conexões com a instituição escolar.

\section{AANTROPOLOGIAE O ESTUDO DA FAMÍLIA E DO PARENTESCO}

Desde o início de suas pesquisas de campo no começo do século XX, os antropólogos dedicaram-se a estudar sociedades diferentes daquelas onde viviam e elaboraram um conjunto de recursos teóricos e metodológicos para descrever e analisar o modo de vida das populações dessas sociedades.

Ao longo de pesquisas e reflexões, que tinham um dos cernes não propriamente na família, mas nas relações de parentesco, os antropólogos constataram que a família não era uma unidade natural, lastreada em determinantes de ordem biológica, mas estava fundada em regras culturais, era estabelecida no decorrer da vida social.

Essa desnaturalização da família veio a constituir o eixo fundamental dos estudos sobre família, e não apenas das análises antropológicas, visto que foi incorporada por outras áreas do conhecimento e permitiu entender que unidade doméstica não é uma entidade única e imutável, mas assume diferentes configurações em sociedades específicas ao longo do tempo e mesmo no interior de cada sociedade. O reconhecimento da diversidade desses arranjos domésticos permite considerar que família é sempre uma realidade plural embora todas as famílias tenham algumas características comuns.

De fato, no plano empírico não há família, mas famílias, que são múltiplas em seus arranjos; logo, suas dinâmicas variam historicamente conforme as condições socioeconômicas, o repertório cultural, a escolarização, a cor/etnia de seus integrantes.

Malgrado a diversidade de arranjos, a família tem sido definida como unidade de reprodução social (BOURDIEU, 1997; DURHAM, 1983), a qual recobre a reprodução biológica e a social. A unidade doméstica envolve não apenas a procriação, mas a reprodução da existência biológica de seus integrantes, a socialização dos imaturos, os cuidados com eles, a sua ressocialização contínua e a dos demais familiares, uma vez que a vida familiar é um processo de incorporação constante de alterações provenientes da esfera pública, tanto da área econômica quanto da política.

A família, em seu sentido genérico, é simultaneamente grupo e instituição. Como grupo social pode assumir 
diferentes formas de organização e enquanto instituição é regida por normas, valores e representações culturais (THERBORN, 2006). Assim, a família encontra-se simultaneamente no terreno da vida social, referido às relações em seu interior e no plano normativo da cultura, que orienta as modalidades dessas relações, inclusive no plano da subjetividade, de expressão de sentimentos e emoções.

Em função dessa generalidade e pelo fato de estar presente em todas as sociedades, é bastante comum ser encontrada, em diferentes trabalhos, a asserção que a família é algo conhecido e familiar, pois nascemos e crescemos em uma família. Porém, como esclarece Lévi-Strauss (1986), a família é uma instituição que envolve problemas diversos de grande complexidade para sua análise. E essa complexidade pode ser exemplificada pela constatação de seu significado polissêmico, tanto no senso comum quanto nas análises científicas que desafiam e dificultam a conceituação do que é família (SEGALEN, 1999).

Prova disso, é a variação de significados atribuídos à família, conceituada de formas particulares nas áreas de estudos antropológicos, sociológicos, demográficos, históricos e psicológicos e que documentam tanto o interesse por ela por esses campos de saber quanto atestam a importância e a diversidade dessa instituição.

A análise da complexidade da vida doméstica demanda um processo que os antropólogos denominaram olhar antropológico, fundado no estranhamento e no descentramento para se afastar do viés etnocêntrico caracterizado por noções preconcebidas que avaliam a família como entidade natural e não socialmente construída e sujeita a transformações constantes. Por isso, a Antropologia propõe e coloca em prática pesquisas e análises dedicadas a estudar de dentro cada sociedade (ou segmentos dela), para conhecê-la a partir dos princípios constitutivos que a estruturam e a modificam no decorrer de seu percurso histórico e social.

Essas considerações são de vital importância para a compreensão da família, e igualmente do sistema de parentesco, pois ambos não podem ser apreendidos, pesquisados e analisados sem levar em consideração tanto a dimensão interna (ou privada) do plano doméstico quanto suas múltiplas articulações com a esfera externa a ela, ou seja, do espaço público, econômico e político, no qual se insere.

Ao mesmo tempo, é mais do que imperioso considerar que a vida doméstica não está rigidamente determinada por constrangimentos e pressões macroestruturais do universo público; mas, em seu interior, há espaço para contestar e recriar suas relações. Portanto, a família não pode ser avaliada como realidade empírica cuja existência é meramente determinada "de fora" e, por outro lado, os arranjos domésticos não são perenes, mas passam por sucessivos processos de transformação. 


\section{FAMÍLIAS NA SOCIEDADE BRASILEIRA CONTEMPORÂNEA}

No presente, constata-se uma redução na quantidade da família nuclear - composta por marido, esposa e filhos -, que, conforme o censo do Instituto Brasileiro de Geografia e Estatística correspondia, em 2010, a 49,4\% dos domicílios brasileiros. Paralelamente, novas modalidades de família tendem a aumentar como as monoparentais, que contam com apenas um cônjuge residindo com filhos. Em versão matrifocal - compreende mãe e filhos, frutos de uma ou de várias uniões vivendo juntos - representa $12,2 \%$ dos arranjos domésticos. Já as famílias patrifocais reúnem pai e filhos convivendo em um domicílio, e correspondem a $1,8 \%$ dos modos de ordenação doméstica (IBGE, 2010). Embora essa proporção seja reduzida, há certa tendência ao aumento, considerando-se que a área jurídica tem, em certos casos, concedido a guarda dos filhos ao pai e revela uma das formas de interferência do Estado na organização familiar.

Essa nova postura altera aquela predominante até recentemente segundo a qual a guarda dos filhos cabia à mãe e, também, mostra o modo de compreensão da realidade doméstica por parte do Judiciário, mais afinado com a realidade atual, visto que é acompanhada pela legitimação de uniões consensuais, conferindo aos parceiros igualdade de estatuto legal comparável às famílias criadas pelo casamento civil.

Outra forma de arranjo é representada por famílias ampliadas, fruto de incorporação de outros parentes à família nuclear e que, em certos momentos, podem deixá-la por diferentes razões, seja por casamento, mudança de localidade ou para conviver com outras pessoas. São também unidades transitórias que podem, eventualmente, reverter ao arranjo nuclear e correspondem a 12,6\% dos domicílios (IBGE, 2010). As famílias recompostas criadas pelo recasamento civil ou por união consensual de um ou de ambos os parceiros e quando há pelo menos um filho de união anterior, seja da mulher ou do marido, totalizam 16,3\% dos domicílios (IBGE, 2010).

Por outro lado, na análise de arranjos domésticos é importante considerar que Lévi-Strauss (1986) acrescenta, em sua definição, que família é um grupo de convivência no qual sentimentos psicológicos diversos estão presentes, o que remete à dimensão da subjetividade e da expressão desses sentimentos.

Sentimentos manifestam-se em diferentes dimensões da vida familiar. Cuidados com idosos, doentes, inválidos, supõem habilidades femininas na consecução dessas atividades e incluem, ainda, outro tipo de atributo, este situado na dimensão afetiva. Nesse caso, persiste a suposição de que as mulheres são naturalmente qualificadas para o desempenho desses cuidados, pois dispõem da capacidade afetiva para executá-los. Dessa forma, além de prestarem 
cuidados materiais, as mulheres realizam, segundo Mcnahon (1993), o "trabalho emocional" ou, conforme Gilligan (1982), são "tecelãs" das relações de parentesco.

A dimensão dos afetos pode ser, ainda, apreendida na própria organização das relações domésticas. A família - qualquer que seja sua forma de arranjo - é constituída por pessoas que mantém entre si relações de cunho personalista, opostas às formas de relacionamento formal que imperam no universo público. Essas relações certamente encontram maior possibilidade de expressão no cenário doméstico, e seus componentes são indivíduos, com suas idiossincrasias e particularidades, com vontades e desejos próprios, e que, simultaneamente, ocupam posições estruturalmente dadas e hierarquizadas, e estas, muitas vezes, são conflitantes entre si. Isso coloca a questão do embate entre interesses individuais diversos de cada um dos familiares e entre esses anseios e o "familismo", o interesse coletivo da família como um todo.

Ainda na dimensão interna da família, os conflitos podem ser ilustrados por disputas entre marido e esposa, pais e filhos e entre irmãos, que compõem a "fratria", e que se expressam na oposição entre os desejos de cada componente da família em relação àquilo que é considerado interesse da entidade doméstica, enquanto grupo. Nesse caso, aspirações individuais, de maior liberdade filial e de consumo de bens materiais - sejam elas de filhos, marido ou esposa -, entram em colisão com aquilo que é projeto coletivo de vida familiar.

Esses confrontos se expressam no controle parental sobre atividades da prole e na contenção de consumo individualizado que é colocado em segundo plano para atender a projetos coletivos da família, como aquisição de bens que suprem necessidades de todos. Bourdieu (1997) explicita que a duplicidade de aspirações, muitas vezes contraditórias e conflitantes, dos membros da família remete às forças de fusão, representadas pelo familismo e se opõem às vontades de seus integrantes, isto é, às forças de fissão. No entanto, é necessário pontuar que ambas, fusão e fissão, estão também estruturalmente dadas e tensionalmente articuladas já que são elementos constitutivos da dinâmica familiar (BOURDIEU, 1997).

Por conseguinte, famílias, na concretude de suas existências, não podem ser apreendidas segundo um modelo teórico unilinear, visto que a vida doméstica é constante fluxo, ou melhor, é um processo marcado por eventos sociais, tais como rupturas e novas uniões ou casamentos, e por outros acontecimentos naturais, por exemplo nascimentos e mortes.

\section{A PRODUÇÃo NACIONAL SOBRE FAMÍLIA}

Os estudos sobre família no Brasil encontram na obra de Freyre (1961) Casa Grande \& Senzala: formação da família brasileira sob o regime de economia patriarcal, 
publicada em 1933, uma referência constante enquanto modelo interpretativo. Esse autor analisa a constituição da família patriarcal dos grandes proprietários de terra e de escravos, cuja forma de organização passa a ser considerada como arranjo doméstico prevalecente no conjunto da sociedade brasileira.

Mais do que realidade empírica, documentada por meio de elementos históricos, a família patriarcal foi convertida em modelo da família brasileira e confunde-se com ela. É desse modo, como representação da família, que o modelo gerado por Freyre foi difundido e incorporado às análises e, até hoje, apesar das críticas (CORREA, 1982; SAMARA, 1983, 1987) é, ainda, referencial para pesquisas e para a reflexão teórica.

A análise da família patriarcal foi retomada por Candido (1951), em artigo intitulado $A$ família brasileira. Nesse texto, documentação e análise vão além do período estudado por Freyre, pois avançam até a primeira metade do século XX e trazem informações sobre famílias do centro e do sul do país, onde a influência paulista foi grande, mas é pouco discutida por Freyre. Se o título sugere a intenção de Candido de construir uma análise explicativa da família brasileira, os dados históricos sobre a organização das unidades domésticas no centro e no sul do país mostram variações na família patriarcal e mudanças que ocorrem com a urbanização e a migração para o meio urbano, que iniciaram ainda no final do século XIX.

Arranjos familiares diversos estiveram presentes na constituição das famílias brasileiras, como a historiografia tem documentado (DIAS, 1984; MARCÍLIO, 1974; SAMARA, 1983, 1989; SILVA, 1984). Desde a da década de 1970 estudos historiográficos começaram a questionar a difusão do modelo da família patriarcal e aparecem em maior número na década seguinte, documentando, já no final do século XVIII, a diversidade de formas de arranjo familiar, em especial no sul do país (SAMARA, 1983, 1987, 1989; DIAS, 1984). Nessa área, conviveram famílias monoparentais chefiadas por mulheres e que resultavam, em grande parte, de uniões consideradas ilegais como "casamentos pela lei da natureza" (SILVA, 1984), mancebia ou concubinato, devido ao alto custo do casamento religioso. No estado de São Paulo, os dados reunidos por Samara (1989) para o século XIX mostram a predominância de famílias nucleares.

Por sua vez, o trabalho de Costa (1983) deslocou o enfoque da pesquisa para a área urbana que mais se modernizava no país e mostrou a emergência de um tipo de família próximo ao da família nuclear burguesa, no Rio de Janeiro no final do século XIX e que estaria relacionado à ação dos médicos higienistas em associação com o Estado.

Denunciando os males do modelo patriarcal e, também, em nome da higienização da família, os médicos concitavam as pessoas a incorporarem novos padrões de ordenação da vida familiar. Condenavam inicialmente o 
casamento entre homens mais velhos e mulheres jovens, às vezes quase impúberes, denunciavam a prostituição como fonte de doenças transmitidas pelo marido à esposa e criticavam celibatários, libertinos, homossexuais e mulheres mundanas.

Procurava-se, assim, proceder à privatização da família, em nome de uma prole sadia, física e emocionalmente. Ao mesmo tempo, essa privatização tinha a intenção de confinar a mulher às atividades maternas, aos cuidados com o marido e com os filhos. Em nome do conhecimento científico da época e de uma concepção de amor familiar recriavam a subordinação feminina e contribuíam para a difusão da representação acerca da naturalidade dos atributos femininos e masculinos.

Nos anos 1970 e 1980, juntamente com o avanço da Historiografia, Antropologia e Sociologia, a família foi retomada como objeto digno de estudo, o que leva a se discutir o contexto social e político da sociedade brasileira.

Ainda sob a ditadura militar, os estudos na área das Ciências Sociais na década de 1980, sobretudo da Sociologia, mas não tanto da Antropologia, estavam voltados para temas considerados políticos ou politizados. Procurava-se discutir as condições da classe operária, dos movimentos sociais, inclusive aqueles ligados às Comunidades Eclesiais de Base com atuação questionadora da realidade social e política vivida no país. Apesar das limitações impostas pelo regime militar, essa década foi um período de efervescência política muito grande e vários estudos debruçaram-se sobre possibilidades de transformação da sociedade brasileira.

Nesse contexto social e acadêmico, os interesses de pesquisa voltaram-se para temas políticos de caráter macroestrutural e as famílias eram avaliadas como esfera social cujo estudo não traria contribuição para a compreensão dos problemas do país e eram consideradas repositórios de tradições e do conservadorismo.

A principal limitação ao estudo da família tinha caráter político-ideológico e consistia no fato de ela ser avaliada como organização a serviço da dominação de homens sobre mulheres e de adultos sobre crianças e jovens, e supunha-se que seu estudo contribuía para ocultar a luta de classes (DURHAM, 1980). Essa forma de interpretar o cenário doméstico incidia ainda com maior intensidade sobre famílias de camadas médias, consideradas as mais conservadoras e as que, mesmo de modo indireto, colaboravam para a manutenção do regime militar.

Foi nesse contexto social e político que os estudos sobre família lentamente começaram a emergir e a conquistar legitimidade tanto social quanto no plano acadêmico a partir dos anos 1970, sobretudo porque se voltavam para pesquisas sobre famílias da população de baixa renda, de camadas populares.

As pesquisas procuravam desfazer o mito de que essas unidades domésticas meramente reproduziam o instituído e estavam, consequentemente, contaminadas por uma 
prática tradicionalista, fundada na ideologia da classe dominante e eram politicamente conservadoras, atreladas a um suposto passado rural, que as impedia de adequaram-se a um meio urbano em profunda transformação.

Nas áreas de Antropologia e Sociologia, as investigações dedicaram-se inicialmente a investigar famílias de trabalhadores urbanos, integrantes do que era designado alternativamente ora como população pobre ou de baixa renda, ora como camadas ou classes populares (BILAC, 1978; FAUSTO NETO, 1982; MACEDO, 1979; WOORTMANN, 1987; DURHAM; CARDOSO, 1977), além de outros estudos que não tratavam diretamente da entidade doméstica, mas de trabalhadores pobres em sua relação com a família (CALDEIRA, 1984; ZALUAR, 1985).

$\mathrm{O}$ que as pesquisas sobre famílias de trabalhadores urbanos constataram foi a importância atribuída à unidade doméstica que não estava fundada em uma valorização de um modo de vida tradicional, nem apegada a valores conservadores provenientes do meio rural os quais sobreviveriam na área urbana. Antes, o apego a determinados modos de sociabilidade familiar resultava do próprio enfrentamento das dificuldades encontradas por essas famílias. A valorização e a importância atribuídas aos parentes criavam vínculos de solidariedade proporcionados pelas relações de parentesco e reforçavam, consequentemente, a importância atribuída à família. De fato, os parentes constituíam uma rede de apoio aos migrantes para obterem informações para conseguir moradia, para se locomoverem na cidade, para terem acesso a serviços de saúde e a escolas e para se inserirem no mercado de trabalho urbano e burocratizado, que demandava escolarização mínima e mão de obra portadora de certos atributos que os migrantes rurais não dispunham.

Os fundamentos do olhar antropológico - ancorados no estranhamento e no distanciamento do que era supostamente familiar e conhecido - permitiram afastar o viés etnocêntrico e conhecer o cotidiano de migrantes e de pobres urbanos evidenciando que essas famílias não estavam presas a um passado rural, mas procuravam integrar-se ao sistema produtivo regido por mecanismos formais, diversos dos vigentes no campo.

Desse modo, a análise da relação entre família e a inserção de seus integrantes na esfera pública, vale mencionar, no mercado de trabalho urbano em processo de transformação econômica em uma sociedade regida por um regime repressivo, alçou a unidade doméstica como grupo relevante para estudos.

Famílias de camadas médias, consideradas política e ideologicamente conservadoras, surgiram mais lentamente nas pesquisas (BARROS, 1987; BRUSCHINI, 1986; ROMANELLI, 1986; SALEM, 1980; VELHO, 1973). Para melhor situar a emergência desses estudos, é necessário considerar que, apesar da repressão política, as décadas de 1970 e 1980 foram marcadas por muita efervescência 
no plano da renovação de normas culturais relacionadas à vida familiar e à sexualidade.

Em boa medida, as pesquisas sobre essas famílias direcionaram-se para um segmento dessas camadas portador de modos alternativos de vida e analisaram as transformações ocorridas, dando ênfase ao ingresso das mulheres no mercado de trabalho, ao advento de correntes dos movimentos feminista e ao individualismo desse segmento específico.

Se a maior parte das famílias das camadas médias continuava apegada a valores e normas convencionais, havia um contingente de integrantes das camadas médias com nível superior de escolaridade que procurava se desligar de um modo de vida conservador e procurava organizar a vida privada e as suas relações afetivas em outros moldes.

Foi nessa época que emergiram correntes do movimento feminista que contribuíram para a discussão da condição feminina e da submissão da mulher no conjunto da sociedade e no interior da família. A difusão dessas novas interpretações - embora lenta e limitada a segmentos mais escolarizados - proporcionou a discussão de modalidades alternativas de relações entre os sexos e, na família, trouxe mais elementos para promover a revisão das concepções tradicionais sobre a unidade doméstica.

Em outra esfera da vida social, melhor definindo, no plano da educação, nas décadas de 1970 e 1980 ocorreu uma imensa expansão de estabelecimentos de ensino superior privados. Houve um incremento muito grande dessas instituições, particularmente nos cursos das Ciências Sociais, sobretudo no período noturno, englobando áreas como Letras, História, Psicologia, Pedagogia, Direito que não exigiam investimentos de vulto em infraestrutura e equipamentos e, em grande parte, destinados ao público feminino e à população com poucos recursos financeiros (ROMANELLI, 1986).

Ao mesmo tempo, avanços no conhecimento científico proporcionaram a difusão de métodos contraceptivos que permitiram separar relação sexual de reprodução biológica. Descolou-se integralmente a vida sexual das pessoas da reprodução biológica, e isso teve consequências expressivas. A adoção desses métodos, inicialmente incorporados por mulheres das camadas médias, foi se difundindo gradativamente para outros segmentos da população repercutindo nas relações amorosas, na reprodução biológica e na forma de organização das relações familiares.

De certo modo, as mulheres das camadas médias com maior nível de escolarização e que ingressaram no mercado de trabalho, inclusive favorecidas pela ampliação de cursos no ensino superior, tiveram papel pioneiro na renovação da vida familiar.

Pesquisas sobre famílias das camadas populares e médias dedicavam-se a entender o modo de vida dessas unidades, analisando suas relações internas, a vida privada. As questões centrais desses estudos eram as relações 
entre seus integrantes, os vínculos conjugal e parental, a reprodução biológica, a composição do orçamento doméstico, o exercício da autoridade e do poder, os projetos para o futuro.

Um dos resultados expressivos dessas pesquisas foi demonstrar que as camadas médias e populares não constituíam entidades homogêneas mas eram compostas por segmentos social, cultural e economicamente diferenciados, o que repercutia nas relações entre famílias e escolas. E, ao mesmo tempo, as pesquisas constatavam que as famílias não eram entidades submetidas a pressões macroestruturais do universo público, e sim, configuravam-se como espaço de criatividade, de renovação constante para enfrentar e solucionar tais pressões.

Em suma, longe de ser mera reprodução do social, as famílias eram analisadas como constituídas por sujeitos atuantes que se empenhavam em resolver seus problemas internos, bem como aqueles derivados de sua vinculação com o domínio público.

\section{FAMÍLIAS E ESCOLAS}

Embora haja um número expressivo de estudos sobre famílias de camadas populares e de suas relações com a escola - como os de Braga (2012), Portes (2011) e Zago (2000, 2011, 2013) - que deram contribuição significativa para a descrição e a análise desses vínculos, há alguns pontos que merecem discussão para aprimorar e aprofundar a análise.

Um dos problemas em alguns estudos sobre família escola é a tendência presente no senso comum e entre agentes educacionais de desqualificar as famílias das camadas populares, rotulando-as de desestruturadas. Essa representação preconceituosa tende a desconsiderar a especificidade do modo de vida dessas famílias, sua alteridade, imputando a elas o rótulo de desestruturadas e que supostamente não cuidam adequadamente dos filhos e da escolarização destes (ROMANELLI, 2003).

$\mathrm{Na}$ verdade, tal representação negativa incide sobre famílias pobres e tende a considerar que essa suposta desestruturação não ocorre em famílias de camadas médias. Ora, famílias destas camadas também enfrentam problemas com filhos, os quais podem ser alunos com pouco interesse pelos estudos, com mau desempenho escolar e envolvidos com criminalidade e consumo de drogas.

O recurso ao olhar antropológico, a incorporação do estranhamento nas análises, pode trazer uma forma de se pesquisar e analisar essas famílias "de dentro", procurando conhecer como organizam as relações entre seus integrantes e o processo de escolarização dos filhos.

Outra dificuldade nos estudos sobre família e escola reporta-se ao fato de a unidade doméstica ser tratada em alguns trabalhos como entidade genérica, desconsiderando as especificidades das configurações que assume e as condições socioeconômicas e culturais que ordenam as relações domésticas. 
${ }^{1}$ Embora escassos, alguns estudos - como os de Balarini e Romanelli (2012), Glória (2005) e Zago (2013) - tratam da importância dos irmãos no processo de escolarização.
Como já argumentou Durham (1983), a família tende a ser tratada de modo metonímico nas representações do senso comum e nas análises sobre ela. Assim, família tanto pode referir-se à mãe, ao pai e a irmãos quanto pode englobar os mais diversos parentes. É comum encontrar, em vários estudos, tal utilização metonímica quando os sujeitos de pesquisas referem-se à família como sujeito coletivo, sem que explicitem o modo como cada um de seus integrantes atua nas relações familiares.

A ausência de precisão no uso do termo família tende a reificar a unidade doméstica e dificulta a compreensão do modo como os pais ou a mãe e o pai individualmente atuam no processo escolarizador. E, ainda mais, nota-se a escassa presença da importância dos irmãos, que compõem a fratria, nesse processo ${ }^{1}$.

Desse modo, família torna-se um termo genérico que oculta a atuação de cada integrante da organização doméstica na escolarização dos filhos. Se a família é importante na escolarização dos filhos das camadas populares, a diversidade no interior dessas unidades precisa ser avaliada na pesquisa e na análise do processo de escolarização.

O exame de algumas pesquisas indica que elas são direcionadas para se ouvir, sobretudo, as mães. E isso, evidentemente, faz a ação familiar ser reduzida à posição e à atuação materna nas análises. Logo, não se investiga o modo como o pai atua na escolarização dos filhos. Esse enviesamento privilegia a postura materna e reproduz concepções naturalizantes do senso comum que tendem a atribuir à mãe a maternagem, os cuidados e a socialização dos filhos, o acompanhamento de suas atividades escolares.

Devido a isso, os estudos sobre família e escola tendem a afastar o pai da cena doméstica. Este é considerado como autoridade, provedor, autoritário e suas relações com os filhos, seja nos cuidados com eles, que implicam a paternagem, seja no processo socializador e de escolarização são reduzidos e considerados pouco importantes nas pesquisas.

Portanto, é relevante discutir o processo socializador que transmite aos filhos um conjunto de orientações que contribuem para a configuração da identidade de gênero, isto é, o que é ser mulher e o que é ser homem. Ser mulher, ser menina é brincar com bonecas, é cuidar dos irmãos e, se for de família pobre, deve, ainda, aprender a cuidar da casa, cozinhar e executar outras tarefas domésticas qualificadas como femininas. Desse modo, desde muito cedo, as mulheres são preparadas para assumir atribuições consideradas não somente como femininas, mas que são qualificadas como elementos naturais e constitutivos da feminilidade. Assim, a identidade de gênero feminina é orientada para os cuidados de maternagem e os meninos não aprendem a paternar (GILLIGAN, 1982).

Como alguns estudos documentaram (BRUSCHINI; RICOLDI, 2009; CARVALHO; SENKEVICS; LOGES, 2014), as mães de famílias de camadas populares e 
médias tendem a socializar as filhas para se desincumbirem de várias tarefas domésticas, o que tende a reproduzir a assimetria entre homens e mulheres. Se, por um lado, as mães criticam seus maridos por não dividirem com elas os afazeres domésticos e condenam a desigualdade entre ambos, por outro lado, socializam suas filhas para assumirem parte desses trabalhos, reproduzindo a desigualdade que condenam no interior da família.

A dificuldade enfrentada pelo pai para paternar, socializar, orientar e acompanhar os filhos em suas obrigações escolares funda-se na representação de que tais atribuições devem ser desempenhadas pela mãe. E o próprio processo socializador tende a enfatizar a feminização de tais tarefas, como se elas fizessem parte de uma suposta natureza feminina.

Assim os homens enfrentam dificuldades para paternar os filhos; porém, essa dificuldade é socialmente produzida e não faz parte nem da natureza feminina nem da masculina, e os homens podem aprender a exercer tais funções. Ademais, esse aprendizado de tarefas domésticas é mais visível e patente em famílias das camadas populares quando as filhas são incumbidas pelas mães que exercem atividades remuneradas fora de casa a assumirem atribuições que seriam exercidas por elas. Certamente, isso não significa que os filhos não desempenhem tais atribuições. Contudo, isso tende a ocorrer quando não há filhas ou quando estão em uma faixa etária que dificulta executarem tais tarefas.

Apesar dessa presença limitada no cenário doméstico, algumas pesquisas como as de Cintra (2014) e Donoso (2015) demonstraram que o pai de famílias de camadas populares com escolarização reduzida é bastante presente no acompanhamento de tarefas escolares e na escolha do estabelecimento de ensino. Se as mães tomam a iniciativa de procurar o que elas consideram as melhores escolas para os filhos, o pai também participa desse processo e, inclusive, discute e negocia com a mãe, procurando obter informações, junto à sua rede de relações pessoais, sobre o estabelecimento escolar no qual seus filhos estudarão. Ao mesmo tempo, os dados dessas pesquisas revelam a forma como o pai incentiva a escolarização dos filhos e como estimula estes a prosseguirem os estudos em cursos superiores a fim de que possam atingir escolarização mais elevada que a dele e exercer atividades profissionais mais bem remuneradas.

A atuação do pai na paternagem e na socialização dos filhos torna-se mais patente nas famílias patrifocais embora haja escassez de estudos sobre esse arranjo familiar. Em pesquisa com pais de famílias patrifocais das camadas populares com escolarização reduzida e rendimentos relativamente precários, Abade (2014) constatou que, embora o pai crie os filhos com dificuldade e sem a presença da mãe, sente orgulho por ser capaz de cuidar deles e de superar os limites de uma condição para a qual não fora previamente preparado. 
${ }^{2}$ Embora pouco presente nos estudos sobre relações entre família e escola, o número 36 de 2010 de Educar em Revista traz o dossiê "Cognição, Afetividade e Educação". Nessa edição, há artigos abordando a importância da afetividade nas atividades educacionais, que podem ser acessados em: <http://revistas.ufpr.br/educar/issue/view/935/showToc $>$.
Todavia, é necessário pontuar que a diversidade no modo de acompanhar e orientar a escolarização dos filhos também está presente em famílias das camadas médias apesar da carência de estudos para se apreender o modo de atuação do pai nessas famílias.

Nesse ponto, é necessário introduzir a importância dos afetos no processo de escolarização, questão pouco discutida e analisada nas pesquisas sobre as relações entre família e escola ${ }^{2}$.

E essa instância da vida afetiva pode ser objeto de discussão a partir de duas perspectivas. Uma delas, analisando como os afetos na família podem contribuir para o sucesso na escolarização dos filhos e outra voltada para buscar apreender a presença dos afetos na dinâmica das relações vividas no estabelecimento escolar.

Famílias são espaços de proteção, de amparo, mas não são um ninho de amor e de afeto; afinal, são atravessadas por tensões, conflitos, brigas, disputas e, inclusive, ódios intensos que muitas vezes levam à prática de violência contra mulheres, crianças, adolescentes e idosos. Entretanto, de qualquer modo, é no interior da família que as pessoas conseguem ter uma existência que não é permeada pela impessoalidade presente em outras instâncias da vida social, como no mundo do trabalho, e que também se manifesta nas relações vividas nos estabelecimentos de ensino.

Dentro da família, as pessoas têm identidades próprias, específicas, vivem uma proximidade muito grande com pai, mãe e irmãos e criam laços bastante sólidos de afetos que são produzidos, criados e podem ser desmontados no decorrer da trajetória da vida doméstica.

$\mathrm{O}$ afeto conjugal resulta de escolha de parceiros e tem caráter de provisoriedade, que é estabelecido pelo contrato civil ou pela união consensual enquanto o elo com os filhos é de outra natureza, é indissolúvel, pois filhos não são objeto de escolha parental.

O pai expressa sua afetividade, embora nem sempre de modo claro e explícito, no modo como orienta os filhos, como os amparam em suas trajetórias escolares proporcionando recursos financeiros para aquisição de material escolar e para outras atividades. E, em certos casos, o pai de famílias das camadas populares e com recursos financeiros escassos mantém os filhos fora do mercado de trabalho para que estes possam dedicar-se somente às tarefas escolares (CINTRA, 2014; DONOSO, 2015).

Todavia, as expressões afetivas do pai nem sempre são apreendidas nas pesquisas e, do mesmo modo, a importância e o significado dos afetos na aquisição do saber não são devidamente interpretados.

Se família e escola são espaços socializadores, são instituições e grupos sociais distintos. Enquanto nesta as relações são informais, pessoais e próximas, as famílias são realidades que mudam ao longo do tempo, pois as relações em seu interior nunca são as mesmas ao longo das trajetórias de seus integrantes. Trajetórias são processos por meio 
do quais cada pessoa vai assimilando novas orientações, novos hábitos, o que altera suas representações e suas práticas sociais (ROMANELLI, 2003). Os pais que criam o primeiro filho não são os mesmos que socializam os outros filhos que, por sua vez, convivem com genitores que adquiriram experiências e, consequentemente, assumem novas formas de orientar os filhos e as relações entre a família e a escola.

Já na escola predomina o formalismo e cada criança é um aluno, visto de modo geral como fazendo parte de determinada classe. As particularidades de cada um se dissolvem e uma das coisas que os pais cobram muito da escola é que seus filhos sejam tratados como se fossem sujeitos singulares, como são na família.

A escola é a instituição dedicada à transmissão de conhecimentos e da formação dos alunos, e possibilita a manifestação de diversas formas de sociabilidade (CANDIDO, 1967) e de convivência com a alteridade, o que pode ampliar o conhecimento de outros modos de relações familiares e de adquirir novos saberes, independentemente do conteúdo escolar.

Afetos não estão presentes unicamente na família, mas expressam-se nas relações vividas no espaço escolar, entre professores e alunos, entre estes e os demais agentes escolares, entre colegas e afetam os vínculos entre todos que ocupam os estabelecimentos de ensino.

As várias formas de sociabilidade entre alunos resultam em agrupamentos, os grupos de pares, como os de estudo, de brincadeiras e jogos e aqueles que se contrapõem à ordem instituída. Porém, são grupos permeados por afetos diversos, nos quais competição, cooperação, solidariedade, amparo se mesclam com sentimentos opostos e podem criar condições favoráveis, ou não, para a troca de informações, de acesso ao saber e ainda para assegurar a continuidade do processo de escolarização (WATARAI; ROMANELLI, 2009).

A importância do afeto foi demonstrada por Piotto (2008), que analisou como alunos universitários provenientes de famílias com poucos recursos financeiros são amparados e assistidos por colegas e como essa expressão de solidariedade é relevante para o prosseguimento da escolarização.

Por outro lado, expressões de afeto entre alunos e professores estão presentes e circulam nas escolas, embora não sejam claramente explicitadas em pesquisas. De qualquer modo, essas questões podem ser aprimoradas com investigações que se dediquem a elas.

Nesse sentido, afetos criados no circuito de sociabilidades variadas no universo escolar podem dificultar ou contribuir com o processo de escolarização. Embora não esteja diretamente relacionada às relações familiares e, por mais importante que seja, essa dimensão da vida escolar tem sido pouco estudada; assim, é essencial que seja investigada em suas múltiplas expressões, o que poderá aportar novos conhecimentos acerca do processo de escolarização. 


\section{ALGUMAS CONSIDERAÇÕES FINAIS}

Este artigo procurou explorar algumas relações entre famílias e escolas visando a desmistificar algumas visões estereotipadas sobre a unidade doméstica e apontar questões que não têm sido objeto de pesquisas e que precisam ser mais bem investigadas para aprofundar os conhecimentos acerca dessas relações.

Nesse sentido, a mobilização do olhar antropológico, fundado no estranhamento e no descentramento do que parece ser familiar e conhecido pode contribuir para trazer à tona temas ainda pouco discutidos nos estudos.

Pesquisar a analisar a posição e atuação do pai e incluir igualmente os irmãos nas análises sobre o processo de escolarização poderá trazer dados e reflexões relevantes e pouco conhecidas para melhor elucidar esse processo.

Percebe-se que os cuidados com filhos e a expressão de afetos foram e ainda tendem a ser considerados como atribuições maternas, que estariam lastreadas em uma suposta natureza feminina. $\mathrm{E}$ isso, obviamente de um lado sobrecarregava - e ainda continua a sobrecarregar - as mulheres e, por outro lado, dava a elas poder de decisão na vida familiar.

O que diversas pesquisas tornaram patente foi mostrar um empenho muito grande por parte das mães em excluir o pai de determinadas atividades domésticas, alegando falta de competência paterna para exercê-las. E isso é bastante vantajoso para os homens que ficam dispensados de assumirem afazeres caseiros; mas, se não os exercerem, não poderão aprender e adquirir habilidades para cuidar dos filhos, para paterná-los e para acompanhar sua escolarização.

Ademais, a dimensão da vida afetiva familiar e a importância da manifestação e expressão de afetos no processo escolarizador têm sido objeto de escassa discussão; por isso, são necessárias investigações mais acuradas. Do mesmo modo, formas de sociabilidade entre alunos no espaço da instituição escolar merecem investigações e análises para que se possa apreender sua importância no processo de aprendizagem.

Relações nas famílias, nas escolas e entre ambas envolvem múltiplas dimensões - nem sempre claras e evidentes para os pesquisadores -, e demandam uma postura investigava e sempre alerta para fatos aparentemente pouco relevantes a fim de que se construam novas formas de conhecimento acerca dessas relações que estão em constante processo de transformação.

\section{REFERÊNCIAS}

ABADE, Flávia. Famílias patrifocais: paternagem e socialização dos filhos. 2014. 91 f. Dissertação (Mestrado em Psicologia) - Programa de Pós-Graduação Psicologia. 
Faculdade de Filosofia, Ciências e Letras, Universidade de São Paulo, São Paulo, 2014.

BALARINI, Fernanda Belinassi; ROMANELLI, Geraldo. O processo de escolarização de irmãos de acordo com a posição na fratria. Práxis educacional, v. 8, n. 12, p. 61-79, 2012.

BARROS, Myriam Lins de. Autoridade e afeto. Rio de Janeiro: Zahar: 1987.

BILAC, Elisabete Dória. Famílias de trabalhadores: estratégias de sobrevivência. São Paulo: Símbolo, 1978.

BOURDIEU, Pierre. O espírito de família. In: BOURDIEU, Pierre. Razões práticas: sobre a teoria da ação. Campinas: Papirus, 1997. p. 124-135.

BRAGA, Maria José. O bom desempenho escolar em meios populares: um elemento para uma definição e alguns dados de pesquisa. Sociologia da educação, Ed. Especial, p. 107-124, 2012.

BRUSCHINI, Maria Cristina Aranha. Estrutura familiar e vida cotidiana na cidade de São Paulo. 1986. 389 f. Tese (Doutorado em Sociologia) - Programa de Pós-Graduação em Sociologia, Faculdade de Filosofia, Letras e Ciências Humanas, Universidade de São Paulo, São Paulo, 1986.

BRUSCHINI, Maria Cristina Aranha; RICOLDI, Arlene Martinez. Família e trabalho: difícil conciliação para mães trabalhadoras de baixa renda. Cadernos de Pesquisa, v. 39, n. 136, p. 93-123, 2009.

CALDEIRA, Teresa Pires do Rio. A política dos outros: o cotidiano de moradores da periferia e o que pensam do poder e dos poderosos. São Paulo: Brasiliense, 1984.

CANDIDO, Antonio. A família brasileira. In: SMITH, Thomas Lynn; MARCHANT, Alexander (Org.). Brazil, portrait of half a continent. New York: The Dryden Press, 1951. p. 80-102.

CANDIDO, Antonio. A estrutura da escola. In: PEREIRA, Luiz; FORACCHI, Marialice Mencarini. Educação \& sociedade. São Paulo: Editora Nacional, 1967. p. 107-128.

CARVALHO, Marília Pinto de; SENKEVICS, Adriano Souza; LOGES, Tatiana Ávila. O sucesso escolar de meninas de camadas populares: qual o papel da socialização familiar? Educação e Pesquisa, v. 40, n. 3, p. 717-734, jul./ set. 2014.

CINTRA, Mariana Simões Ferreira. A importância da família, escola e pares no processo de escolha pelo ensino médio técnico. 2014. 121 f. Dissertação (Mestrado 
em Educação) - Programa de Pós-Graduação em Educação, Faculdade de Filosofia, Ciências e Letras, Universidade de São Paulo, São Paulo, 2014.

CORREA, Mariza. Repensando a família patriarcal brasileira (notas para o estudo das formas de organização familiar no Brasil. In: ALMEIDA, Maria Suely Kofes de et al. (Org.). Colcha de retalhos. São Paulo: Brasiliense, 1982. p. 13-38.

COSTA, Jurandir Freire. Ordem médica e norma familiar. Rio de Janeiro: Graal, 1983.

DIAS, Maria Odila Leite da Silva. Quotidiano e poder em São Paulo no século XIX. São Paulo: Brasiliense, 1984 .

DONOSO, Lígia Basílio. Práticas paternas na educação dos filhos: um estudo com pais trabalhadores manuais. 2015. 169 f. Dissertação (Mestrado em Educação) - Programa de Pós-Graduação em Educação, Faculdade de Filosofia, Ciências e Letras, Universidade de São Paulo, 2015.

DURHAM, Eunice Ribeiro. A família operária: consciência e ideologia. Dados: Revista de Ciências Sociais, v. 23, n. 2, p. 201-214, 1980.

DURHAM, Eunice Ribeiro. Família e reprodução humana. In: DURHAM, Eunice Ribeiro et al. Perspectivas antropológicas da mulher 3. Rio de Janeiro, Zahar, 1983. p. 15-43.

DURHAM, Eunice Ribeiro; CARDOSO, Rute Correa Leite. Elaboração cultural e participação social nas populações de baixa renda. Ciência e Cultura, v. 29, n. 2, p. 171-177, 1977.

EDUCAR EM REVISTA. Dossiê: Cognição, Afetividade e Educação, Curitiba, n. 36, p. 1-284, 2010. Disponível em: <http://revistas.ufpr.br/educar/issue/view/935/showToc $>$. Acesso em: 2 ago. 2015.

FAUSTO NETO, Ana Maria Quiroga. Família operária e reprodução da força de trabalho. Petrópolis: Vozes, 1982.

FREYRE, Gilberto. Casa Grande \& Senzala: formação da família brasileira sob o regime de economia patriarcal. Rio de Janeiro: José Olympio, 1961.

GILLIGAN, Carol. Uma voz diferente: psicologia da diferença entre homens e mulheres da infância à idade adulta. Rio de Janeiro: Ed. Rosa dos Tempos, 1982.

GLÓRIA, Dília Maria Andrade. Relação entre escolaridade e diferenças constitutivas das fratrias. Paideia, Ribeirão Preto, v. 15, n. 30, p. 31-42, 2005. 
INSTITUTO BRASILEIRO DE GEOGRAFIA E ESTATÍSTICA. Censo Demográfico 2010. Famílias e domicílios - Resultados da amostra. Rio de Janeiro, 2010. Disponível em <http://www.ibge.gov.br/home/estatistica/populacao/ registrocivil/2008/rc2008.pdf>. Acesso em: 2 ago. 2015.

LÉVI-STRAUSS, Claude. A família. In: LÉVI-STRAUSS, Claude. O olhar distanciado. Lisboa: Ed. 70, 1986. p. 69-98.

MACEDO, Carmen Cinira. A reprodução da desigualdade. São Paulo: Hucitec, 1979.

MCMAHON, Anthony. Male readings of feminist theory: the pscychologization of sexual politics in the masculine literature. Theory and society, n. 22-25, p. 675-695, 1993.

MARCÍliO, Maria Luiza. A cidade de São Paulo. São Paulo: Pioneira, 1974.

PIOTTO, Débora Cristina. Trajetórias escolares prolongadas nas camadas populares. Cadernos de Pesquisa, São Paulo, v. 38, n. 135, p. 701-727, 2008.

PORTES, Écio Antonio. O trabalho escolar das famílias populares. In: NOGUEIRA, Maria Alice; ROMANELLI, Geraldo; ZAGO, Nadir (Org.). Família \& escola: trajetórias de escolarização em camadas médias e populares. 6. ed. Petrópolis: Vozes, 2011. p. 61-80.

ROMANELLI, Geraldo. Famílias de camadas médias: a trajetória da modernidade. 1986. 343 f. Tese (Doutorado em Antropologia) - Programa de Pós-Graduação em Antropologia, Faculdade de Filosofia, Letras e Ciências Humanas, Universidade de São Paulo, São Paulo, 1986.

ROMANELLI, Geraldo. Questões teóricas e metodológicas nas pesquisas sobre família e escola. In: ZAGO, Nadir, CARVALHO Marília. Pinto de; VILELA, Rita Amélia Teixeira (Org.). Itinerários de pesquisa: perspectivas qualitativas em sociologia e educação. Rio de Janeiro: DP\&A, 2003. p. 245-264.

SALEM, Tania. O velho e o novo. Petrópolis: Vozes, 1980.

SAMARA, Eny de Mesquita. A família brasileira. São Paulo: Brasiliense, 1983.

SAMARA, Eny de Mesquita. Tendências atuais da história da família no Brasil. In: ALMEIDA, Angela Mendes de (Org.). Pensando a família no Brasil: da colônia à modernidade. Rio de Janeiro: Espaço e Tempo; UFRRJ, 1987. p. 25-36. 
SAMARA, Eny de Mesquita. As mulheres, o poder e a famíla. São Paulo: Marco Zero; Secretaria de Estado da Cultura de São Paulo, 1989.

SEGALEN, Martine. Sociologia da família. Lisboa: Terramar, 1999.

SILVA, Maria Beatriz Nizza da. Sistema de casamento no Brasil colonial. São Paulo: T.A. Queiroz; EDUSP, 1984.

THERBORN, Göran. Sexo e poder. A família no mundo: 1900-2000. São Paulo: Contexto, 2006.

VELHO, Gilberto. A utopia urbana. Rio de Janeiro: Zahar Editores, 1973.

WATARAI, Felipe; ROMANELLI Geraldo. Escolarização e trabalho de adolescentes do sexo masculino das camadas populares. In: CUNHA, Marcus Vinicius; PASIAN, Sonia Regina; ROMANELLI, Geraldo (Org.) Pesquisas em psicologia. São Paulo: Vetor, 2009. p. 205-232.

WOORTMANN, Klaas. A família das mulheres. Rio de Janeiro: Tempo Brasileiro; Brasília: CNPq, 1987.

ZAGO, Nadir. Quando os dados contrariam as previsões estatísticas: os casos de êxito escolar nas camadas socialmente desfavorecidas. Paideia, v. 10, n. 18, p. 70-80, 2000.

ZAGO, Nadir. Processos de escolarização nos meios populares. As contradições da obrigatoriedade escolar. NOGUEIRA, Maria Alice; ROMANELLI, Geraldo; ZAGO, Nadir (Org.). Família \& escola. Trajetórias de escolarização em camadas médias e populares. 6. ed. Petrópolis: Vozes, 2011. p. 17-44.

ZAGO, Nadir. Agricultura familiar e destinos sociais dos jovens. Entre a permanência na agricultura e a busca de novos horizontes. In: ROMANELLI, Geraldo; NOGUEIRA, Maria Alice; ZAGO, Nadir (Org.). Família \& escola: novas perspectivas de análise. Petrópolis: Vozes, 2013. p. 165-196.

ZALUAR, Alba. A máquina e a revolta: as organizações populares e o significado da pobreza. São Paulo: Brasiliense, 1985 . 